\title{
Influence of the polymeric coating thickness on the electrochemical performance of Carbon Fiber/PAni composites
}

\author{
Carla Polo Fonseca ${ }^{1}$, Dalva Alves de Lima Almeida ${ }^{1 *}$, Mayara Camila Duarte de Oliveira ${ }^{1}$, \\ Maurício Ribeiro Baldan ${ }^{1}$ and Neidenei Gomes Ferreira ${ }^{1}$
}

\author{
${ }^{1}$ Laboratório Associado de Sensores e Materiais, Instituto Nacional de Pesquisas Espaciais - INPE, \\ São José dos Campos, SP, Brazil \\ *dalva.dri@gmail.com
}

\begin{abstract}
Carbon fiber/polyaniline composites (CF/PAni) were synthesized at three different deposition time of 30, 60 and 90 min by oxidative polymerization. The composite materials were morphologically and physically characterized by scanning electron microscopy and by Raman spectroscopy, respectively. Their electrochemical responses were analyzed by cyclic voltammetry, by galvanostatic test, and by electrochemical impedance spectroscopy. The influence of the PAni layer thickness deposited on carbon fibers for the composite formation as well as for their electrochemical properties was discussed. The CF/PAni-30 showed a nanometric thickness with more homogeneous morphology compared to those formed in deposition times of 60 and $90 \mathrm{~min}$. It also showed, from the electrochemical impedance spectroscopy measurements, the lowest charge transfer resistance value associated to the its highest value for the double-layer capacitance of $180 \mathrm{Fg}^{-1}$ making it a very strong candidate as a supercapacitor electrode.
\end{abstract}

Keywords: carbon fiber, polyaniline, composite, supercapacitors.

\section{Introduction}

The development of new materials has been required concerning the application on modern and alternative devices associated to the world energy problem. This problem is not only related to energy shortages, but also to energy sources to minimize the environmental impact ${ }^{[1]}$. In this context, supercapacitors have played an outstanding role in research energy groups, with new promising approaches to produce renewable energy sources besides reducing environmental problems. Supercapacitors and batteries are considered as energy storage devices of equal significance, due to their complementary modes of operation. However, there are distinctions between them with respect to charge storage mechanisms. In the case of supercapacitors there are two possible mechanisms for energy storage: (1) firstly, by the accumulation of charge on the surfaces of the active material, where this process occurs by the electrostatic charge accommodation at the electrical double-layer, through the adsorption of the electrolyte ions on the surfaces of electrically stimulated carbon-based materials; (2) secondly, by the fast and reversible redox or Faradaic reactions during the oxidation/reduction process, where the devices are called as pseudocapacitors, whose electrodes are made up by transition metal-oxides, hydroxides, and/or conducting polymers oxides or conducting polymers, ${ }^{[2-6]}$.

Recently, supercapacitors have played an increasingly important role in applications such as the auxiliary power source in combination with battery electric and hybrid vehicles $^{[6]}$, because they exhibit power densities which are about ten times higher than those of batteries, showing excellent cycling stability even after hundreds of thousands of charge/discharge cycles. Other applications which include their use are: short-time power source for mobile electronic devices, backup power sources for computer memory, cell phones ${ }^{[7]}$, laser pulse, etc. ${ }^{[2,8]}$ which are highly time dependent ${ }^{[3]}$.

Various materials have been studied for applications in supercapacitor such as: (i) carbon; (ii) transition metal oxides, ruthenium and iridium; and (iii) conducting polymers. Among them, conducting polymers are one of the most studied due to their characteristics, such as high electrical conductivity, electrochemical reversibility, low weight, and stability in the air ${ }^{[2-7]}$. Particularly, cconducting polymers such as polyaniline (PAni) ${ }^{[9,10]}$, polypyrrole ${ }^{[11,12]}$, poly(ethylenedioxythiophene) polythiophene ${ }^{[4]}$ have appeared as the most cited in literature. In this context, PAni is a very promising candidate for practical applications due to its reversible control of electrical properties by both charge-transfer doping and protonation, good processability, environmental stability, and low cost.

A major inconvenience in the application of conducting polymers as electrodes in power devices is related to their low stability during cycling, due to the volume changes of the films with the doping/undoping process. This process causes dilatation/reduction on the film volume, breaking its morphology, and, consequently, harming its conductive properties. This stress, which happens during the charge/discharge process of the conducting polymer, occurs mainly when it is polymerized as random form, i.e. with a large amount of crosslinking. To reduce this effect, many authors have used a matrix that serves as a template during the polymer growth $^{[13,14]}$. In this case, the carbonaceous materials have proved to be a great material to orient the conducting polymer polymerization, such as carbon nanotube, carbon fibers and others. 
The synthesis of conducting polymer on carbonaceous material has been cited in the literature by reporting the improvement of its electrical conductivity as well as its mechanical properties in comparison to those of the original polymer matrix ${ }^{[15-21]}$. Recently, the use of porous carbon, carbon nanotubes, or even graphene as a nano-architectural template for synthesis of nano-sized PAni has been reported to enable exceptional conductive properties and to mitigate the cycle degradation issues caused by PAni mechanical problems ${ }^{[14,21]}$. Taking into consideration the above revision, this work presents the PAni deposition on CF through a chemical polymerization at different deposition times of 30 , 60 and 90 min leading to different mass of the conducting polymers on $\mathrm{CF}$ matrix. The $\mathrm{CF} / \mathrm{PAni}$ composites were morphologically and physically characterized by scanning electron microscopy and the Raman spectroscopy, respectively. Their electrochemical responses were analyzed by cyclic voltammetry $(\mathrm{CV})$, galvanostatic test, and electrochemical impedance spectroscopy (EIS) measurements.

Taking into account the techniques mentioned above, the EIS is considered a major one because it provides important information about the electrode interface reactions. The impedance response of electrodes rarely shows the ideal response except for single electrochemical reactions. In the case of materials with heterogeneous surfaces such as composites, the CPE defines inhomogeneity of the surface in the electrochemical EIS experiments and it is reasonable to expect that a better fit for real system is obtained by using $\mathrm{CPE}^{[22,23]}$. The impedance of the constant phase elements is a power-law dependent interfacial capacity defined in Equation 1 as:

$$
Z_{C P E}=1 / Q(j \omega)^{n}
$$

where $Q$ is the frequency independent constant relating to the surface electro active properties, $\omega$ is the radial frequency, the exponent $n$ arises from the slope and its value may change in the range $-1 \leq n \leq 1$, which it is estimated from the slope plot of $\log Z v s$. $\log \omega$. When $n=0$, the $\mathrm{CPE}$ behaves as a pure resistor. When $n=1 \mathrm{CPE}$ behaves as a pure capacitor and $Q$ has units of a capacitance, and represents the capacity of the interface. When $n=-1 \mathrm{CPE}$ behaves as an inductor; while $n=0.5$ corresponds to Warburg impedance $\left(Z_{w}\right)$, which is associated with the domain of the mass transport control arising from the ions diffusion from the electrode/electrolyte interface. Generally, the CPE has been associated to several factors, such as the morphology of the electrode, the presence of the porous, the roughness of polycrystalline material, and the distribution of the relaxation time due to the heterogeneities existing at the electrode/electrolyte interface ${ }^{[24]}$. From the analysis of these elements, it is possible to investigate the electrochemical behaviour of the electrodes and their applicability.

\section{Experimental}

The CFs were cut in the size of $2 \times 1 \mathrm{~cm}$ and weighted. Six samples were prepared for each synthesis, simultaneously. The fibers were fixed at platinum wire and placed in a solution containing purified aniline (Aldrich) by simple distillation (three times) $\left(12.6 \mathrm{mmol} \mathrm{L}^{-1}\right)$ and $1.0 \mathrm{~mol} \mathrm{~L}^{-1} \mathrm{HCl}$, $3.0 \mathrm{~mol} \mathrm{~L}-1 \mathrm{NaCl}$ and cooled to $-10^{\circ} \mathrm{C}$ using an ice bath. Another solution containing $1.0 \mathrm{~mol} \mathrm{~L}^{-1} \mathrm{HCl}, 3.0 \mathrm{~mol} \mathrm{~L}^{-1} \mathrm{NaCl}$ and $0.03 \mathrm{~mol} \mathrm{~L}^{-1}$ ammonium persulfate, $\left(\mathrm{NH}_{4}\right)_{2} \mathrm{~S}_{2} \mathrm{O}_{8}$, was added to the aniline solution at different deposition times of the 30,60 and $90 \mathrm{~min}$ at $-10^{\circ} \mathrm{C}$ with vigorous stirring. The CF/PAni composites were named as CF/PAni-30, CF/PAni-60, and CF/PAni-90 for samples with deposition times of 30, 60, and $90 \mathrm{~min}$, respectively. The composites were washed successively with $1.0 \mathrm{~mol} \mathrm{~L}^{-1} \mathrm{HCl}$, obtaining the conduction sate of the PAni (emeraldine), and deionized water and ethanol several times until the filtrate became colorless. All samples were dried under vacuum for $24 \mathrm{~h}$. After completely dried, the samples were weighed using an analytical balance.

The PAni powder was also synthesized by chemical polymerization using the same solutions of the composites to produce the PAni electrode. The oxidizing agent solution was added with vigorous stirring for $90 \mathrm{~min}$. The precipitate was collected by filtration, and then washed with $1 \mathrm{~mol} \mathrm{~L}^{-1}$ $\mathrm{HCl}$, obtaining the conducting state of the PAni (emeraldine). The PAni electrode was prepared by mixing the PAni powder (90\% wt.) with poly vinylidene fluoride (PVDF) $(10 \% \mathrm{wt}$. $\mathrm{MW}=10^{5} \mathrm{~g} \mathrm{~mol}^{-1}$ ) in N.N.-dimethyl acetamide. The films were obtained by painting the platinum electrode. Prior to the use, the electrodes were dried at room temperature for $72 \mathrm{~h}$.

The morphological characterization was carried out by scanning electron microscopy (SEM) JEOL model JSM-5900LV. The Raman spectra were recorded using a micro - Raman scattering spectroscopy (Renishaw microscope system 2000) in backscattering configuration at room temperature employing $514.5 \mathrm{~nm}$ Ar ion laser.

The composite electrodes were characterized by cyclic voltammetry, by chronopotenciometry, and by electrochemical impedance spectroscopy experiments in the $1.0 \mathrm{~mol} \mathrm{~L}^{-1}$ $\mathrm{H}_{2} \mathrm{SO}_{4}$ solution. The cyclic voltammograms were acquired in a potential scan of the $-0.1 \leq \mathrm{E} \leq 0.78 \mathrm{~V} v s$. $\mathrm{Ag} / \mathrm{AgCl}$ with several scan rates $(1,5,10,25,50,75$ and $100 \mathrm{mV} / \mathrm{s})$. The charge-discharge curves were obtained at three different current densities $\left( \pm 0.50, \pm 0.75\right.$ and $\left.1 \pm 1 \mathrm{~mA} \mathrm{~cm}^{-2}\right)$ within the potential window $-0.1 \mathrm{~V}-0.75 \mathrm{~V}$ vs $\mathrm{Ag} / \mathrm{AgCl}$. All the impedance spectra were recorded at an open circuit potential. The impedance spectra were recorded by applying the ac amplitude of $10 \mathrm{mV}$ and the data were collected in the frequency range from $10^{5}$ to $10^{-3} \mathrm{~Hz}$. The impedance data were analyzed using the Boukamp's fitting program ${ }^{[23,24]}$. All the electrochemical data were obtained with an AUTOLAB - PGSTAT30 potentiostat system.

\section{Results and Discussion}

The SEM images of CF, of PAni powder, and of $\mathrm{CF} / \mathrm{PAni}$ composites are shown in Figure 1. The average diameter of the CF (Figure 1a) was estimated at about $10 \mu \mathrm{m}$ and presented a smooth surface, free of cracking. Moreover, the PAni morphology was composed of plates and clusters with foam aspect, Figure 1b. All the composites prepared by chemical polymerization presented a similar and well-dispersed carbon fiber uniformly enwrapped by the PAni, Figure 1c-h. 


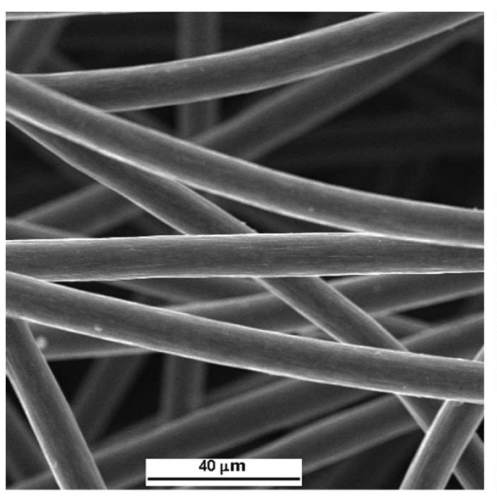

(a)

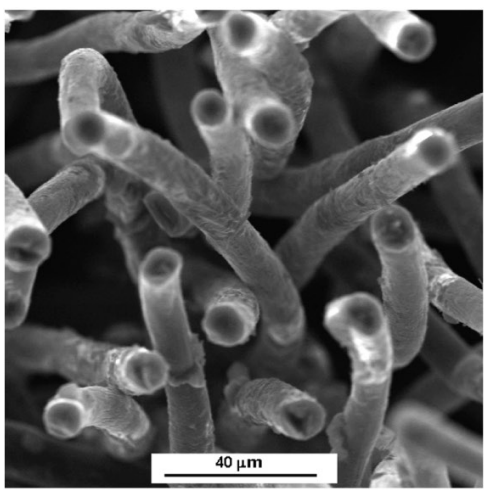

(c)

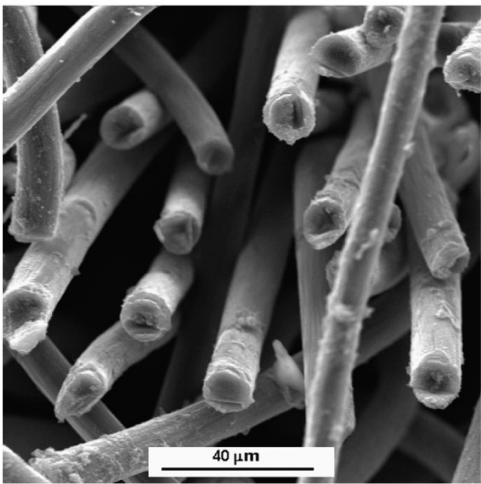

(e)

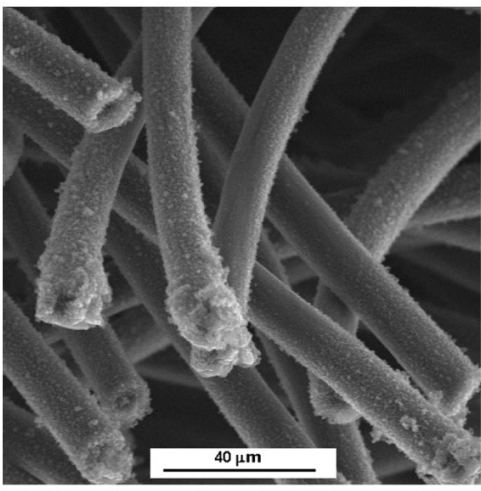

(g)

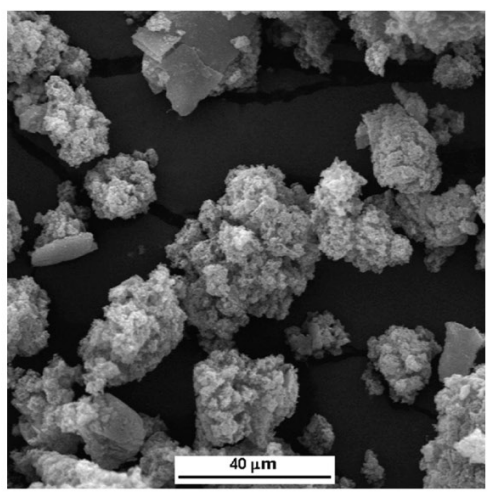

(b)

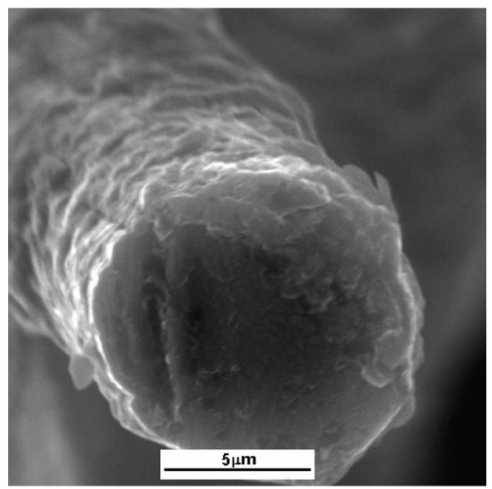

(d)

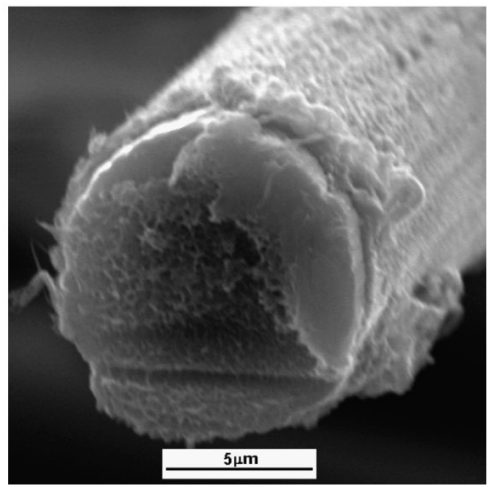

(f)

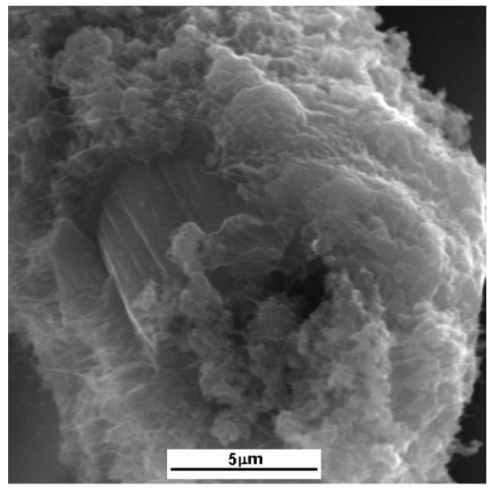

(h)

Figure 1. SEM images of (a) CF, (b) PAni powder, (c,d) CF/PAni - 30, (e,f) CF/PAni - 60, and (g,h) CF/PAni - 90. 
This complete coverage by the PAni on the $\mathrm{CF}$ is related to the Van der Waals interaction between CFs and the PAni by effective interaction between the $\pi$ - bonds of the aromatic ring of PAni and CF. This interaction facilitates the growth of a homogeneous conductive polymer on the carbon fiber, due to the electronic conductivity increase provided by CF.

The PAni thickness increase on the carbon fiber was observed as the deposition time increased. For CF/PAni-30, a homogeneous coating of the nanometer thickness $(84 \mathrm{~nm})$ appeared covering the entire $\mathrm{CF}$ surface. Nonetheless, for composites deposited for 60 and $90 \mathrm{~min}$, the presence of agglomerates among the carbon fibers also occurred. The thickness values of CF/PAni-60 and CF/PAni- 90 were around 0.28 and $1.32 \mu \mathrm{m}$, respectively. This is an indication of their nanometric characteristics loss.

$\mathrm{CF} / \mathrm{PAni}$ composites, carbon fiber, and PAni powder were also characterized by Raman spectroscopy as shown in Figure 2. Raman spectroscopy provides an extremely useful tool to characterize PAni. With this technique it is possible to obtain the structural information, the oxidation state, the doping, the crosslinking as well as the chain conformation of the polymeric compounds ${ }^{[22,23,25]}$. Figure 2 shows the Raman features for: (a) CF,(b) PAni powder, (c), CF/PAni-30, (d) CF/PAni-60, and (e) CF/PAni-90.

The spectrum (a) refers to $\mathrm{CF}$ electrode with a profile graphite-like material ${ }^{[26,27]}$, showing two bands: $\mathrm{D}\left(\sim 1352 \mathrm{~cm}^{-1}\right)$, $\mathrm{G}\left(\sim 1582 \mathrm{~cm}^{-1}\right)$. Nonetheless, the spectrum (a) is compatible with PAN-based CF, i.e., it is the structure of the carbon fibers obtained from polyacrylonitrile precursor graphitized at temperatures around $1000^{\circ} \mathrm{C}^{[27-29]}$, as expected. For all composites analyzed, the spectra are dominated by the PAni spectrum and exhibit characteristic bands of conducting species, mainly CF/PAni-30. The $\mathrm{C}^{-\mathrm{N}^{+}}$band, which is characteristic of emeraldine salt was associated to the splitting in $1320-1370 \mathrm{~cm}^{-1[30]}$. Nascimento et al. have associated the bands around $1324-1375 \mathrm{~cm}^{-1}$ to $\mathrm{C}-\mathrm{N}^{+}$of polarons having different conjugation lengths ${ }^{[31]}$. In general, the CF/PAni composite spectra were dominated by the PAni behavior

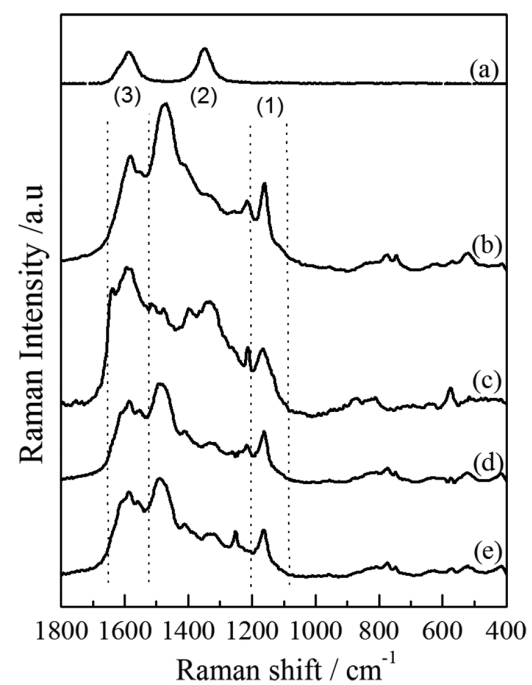

Figure 2. Raman spectra of (a) CF, (b) PAni powder, (c) CF/PAni - 30, (d) CF/PAni - 60, and (e) CF/PAni - 90. indicating a good coating of the conducting polymer on the carbon fibers for the three kinds of composites studied. Considering the spectra region from 1100 to $1210 \mathrm{~cm}^{-1}$, all spectra show the band at $1160 \mathrm{~cm}^{-1}$ that correspond to the $\mathrm{C}-\mathrm{H}$ bending. This band is commonly characterized by the high degree of the PAni oxidation. In addition, for CF/PAni-30 composite, the spectrum is quite different and presents the bands at $1630 \mathrm{~cm}^{-1}$ and at $575 \mathrm{~cm}^{-1}$, which may be associated with the deformation of cross-linkages with a phenazine configuration. These bands were not verified for CF/PAni-60 and CF/PAni-90. Moreover, for these composites, the presence of a strong band at $1480 \mathrm{~cm}^{-1}$ is observed and associated to the $\mathrm{C}=\mathrm{N}$ stretching in quinoid segments. Also, the peak at $1220 \mathrm{~cm}^{-1}$ is ascribed to C-N stretching in the benzoid segments. In the range from $1500 \mathrm{~cm}^{-1}$ to $1650 \mathrm{~cm}^{-1}$ different C-C stretching bands may be assigned to the quinone, phenyl and to semi-quinone structure ${ }^{[32,33]}$.

The electrochemical performance of CF, PAni powder, and CF/PAni composites was analyzed by cyclic voltammetry. Figure 3 shows the cyclic voltamograms of all materials, normalized by the mass of each sample. The cycle performance was not investigated over $0.78 \mathrm{~V}$ vs. $\mathrm{Ag} / \mathrm{AgCl}$ to avoid the PAni degradation. The results show that the CF has a purely capacitive profile assigned to its electric double layer formation (Figure 3 inset). At lower potentials, the reduction process of hydrogen can be observed.

The cyclic voltammetry of the PAni powder shows a poorly defined single redox peak, which has been assigned to the conversion of leucoemeraldine/emeraldine states ${ }^{[32]}$. The emeraldine/pernigraniline transition was not observed in the cyclic voltammogram of Figure 3. Probably, during the PAni electrode formation, the agglomerates were not totally separated making the visualization of other redox couples difficult. Besides, the cyclic voltamograms were performed in the range of potential below the emeraldine/ pernigraniline transition to prevent the PAni overoxidation.

For CF/PAni-30, cyclic voltammograms showed peaks attributed to different oxidation states of PAni. The redox peaks, at a and at a' are assigned to the conversion of leucoemeraldine/emeraldine states at 0.27 and at $0.07 \mathrm{~V}$ vs. $\mathrm{Ag} / \mathrm{AgCl}$, and the beginning of the $\mathrm{b}$ and $\mathrm{b}$ ' peaks are related to the conversion between esmeraldine/pernigraniline.

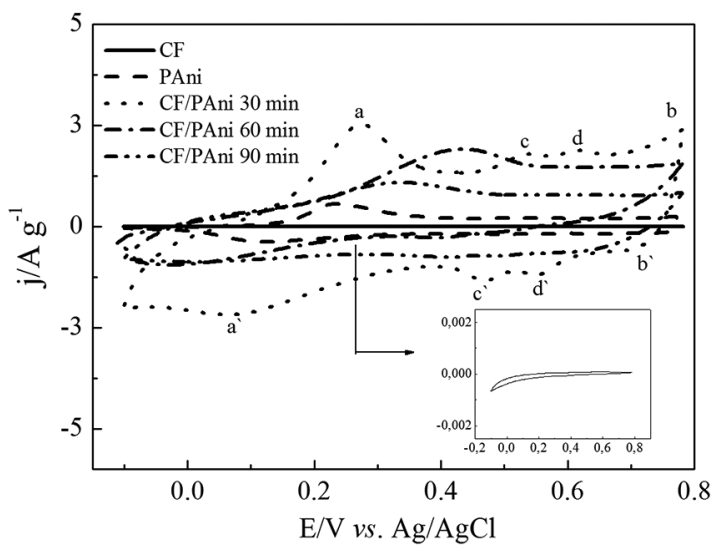

Figure 3. Cyclic voltamograms normalized by the mass of CF, PAni powder, CF/PAni-30, CF/PAni-60, and CF/PAni-90 composites. 
Intermediate peaks were noticed in the region of 0.4 and $0.6 \mathrm{~V}$ vs. $\mathrm{Ag} / \mathrm{AgCl}$ (c / c' and d / d ') which have been attributed to the benzoquinone / hydroquinone (BQ/HQ) pair and to the redox reaction of ortho-aminophenol (PAP) and benzoquinoline (IQ), respectively ${ }^{[34]}$. These processes were related to the PAni degradation.

The PAni redox pairs were not observed for the voltammograms of CF/PAni-60 and CF/PAni-90 due to the presence of the capacitive charging development. This process is characterized by the rectangular format of the voltammograms ${ }^{[24]}$. This fact can be attributed to the increase of the deposition time that causes a disorder in the polymer chains during the PAni film growth and may prevent the faradic processes. CF/PAni-30 composite has the lowest amount of conductive polymer mass, and it presented the highest charge storage capacity. This fact could be related to the close contact of the PAni layer with the carbon fiber facilitating the faradic transport and the capacitive charge across the composite bulk.

The cyclic voltammograms for CF/PAni-30 and for $\mathrm{CF} / \mathrm{PAni}-60$ composites at different scan rates are shown in Figures 4 and 5, respectively. For both electrodes an increase in the peak current (ip) as well as a peak current shift as a function of the scan rate increase were observed. Nonetheless, it is important to point out that for CF/PAni-60 at scan rates higher than $75 \mathrm{mV} . \mathrm{s}^{-1}$ the peak currents disappeared and the redox process was not evident. Similar behavior was observed for CF/PAni-90 composite in the whole range of scan rate studied (not shown) as a reversibility loss.

Firstly, the electrochemical reversibility was evaluated by the ratio between the anodic and the cathodic charges (qa/qc). For a reversible system, the qa/qc must be equal to 1 and it is independent of the scan rate. The CF/PAni-30 composite showed an excellent electrochemical reversibility presenting a qa/qc ratio close to 1 even at high scan ratios. The qa/qc ratio showed a decrease from 1 to 0.85 at $75 \mathrm{mVs}^{-1}$ for the CF/PAni-60 composite. In addition, for CF/PAni-30 and CF/PAni-60- composites the anodic peak shifted to a more negative potential while the cathodic peak shifted to a more positive potential, as expected for quasi-reversible systems ${ }^{[35]}$. However, it was observed that for the same scan rate $\Delta \mathrm{Ep}$ is larger for $\mathrm{CF} / \mathrm{PAni}-60$ than that for $\mathrm{CF} / \mathrm{PAni}-30$. This means that not all ions, which were inserted in the CF/PAni -60 at electroactive sites during the charge process, came out for the discharge process leading to a slower kinetics for this electrode.

The deformations observed in the voltammograms, mainly for scan rate higher than $50 \mathrm{mVs}^{-1}$, can be associated to the electroactivity of these materials and, therefore, to the conformation of polymer chains during the polymerization process. Particularly, for CF/PAni-30 composite, its lowest voltammogram deformation is associated to its strong electroactivity. This behavior may be explained taking into account the high uniformity of its polymeric layer (Figure 1c) also associated to its high conductivity confirmed by the Raman features that are very similar to those of the PAni powder (Figure 2b).

The electrochemical characteristics of these materials, taking into account their electrode/electrolyte interfaces, were also investigated by electrochemical impedance spectroscopy
(EIS) at an open circuit potential. The EIS of CF, PAni, and $\mathrm{CF} / \mathrm{PAni}$ composites were obtained in the range from $10^{-3}$ to $10^{5} \mathrm{~Hz}$. The spectra presented in Figure 6 show the electrolytic properties at high frequency region while at mid

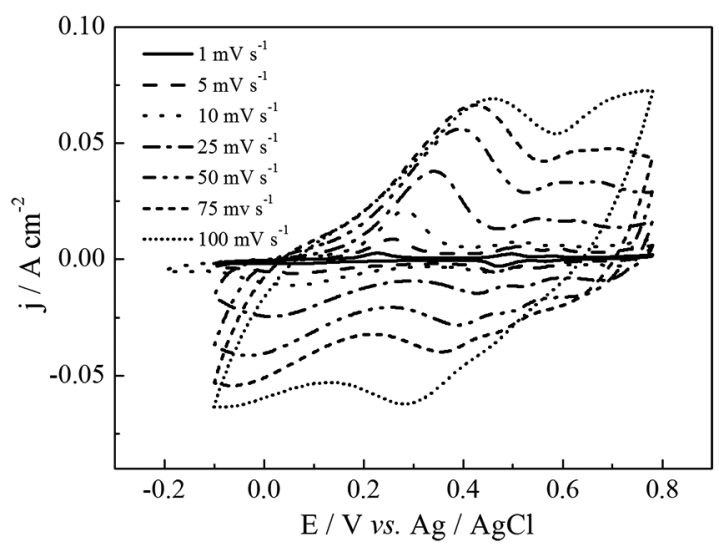

Figure 4. Cyclic voltammograms for $\mathrm{CF} / \mathrm{PAni}-30$ composite at different scan rates.

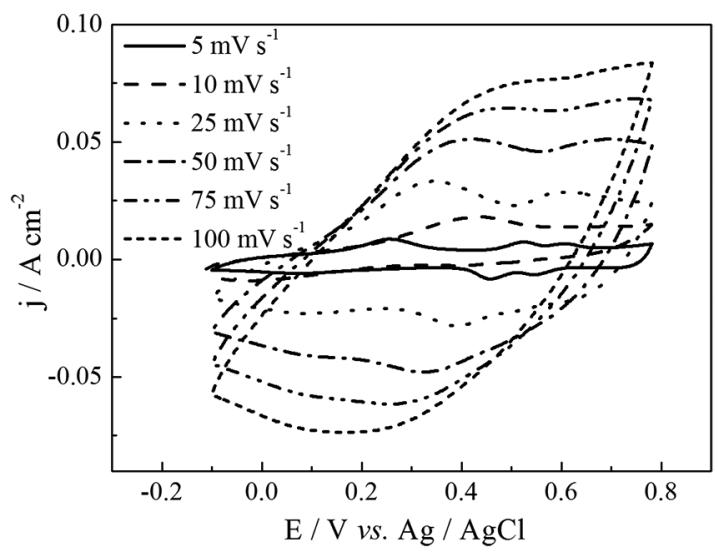

Figure 5. Cyclic voltammograms for CF/PAni-60 composite at different scan rates.

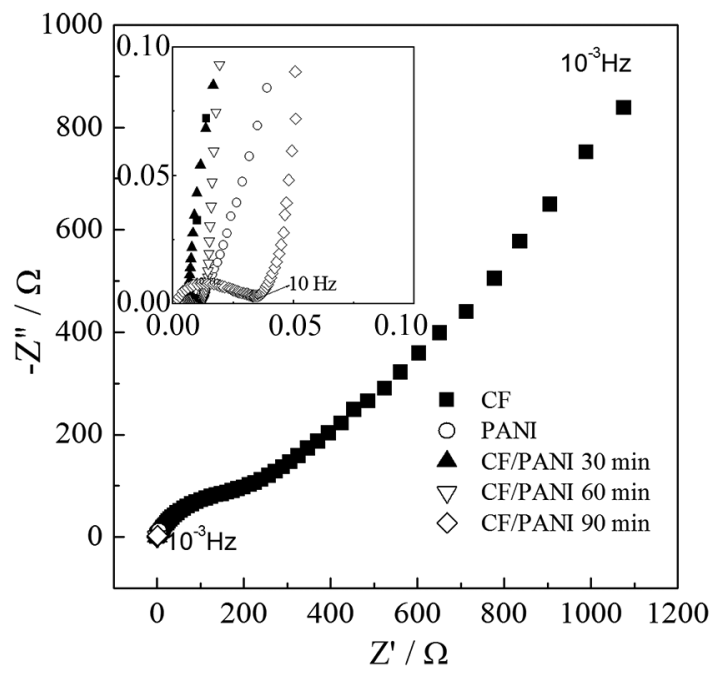

Figure 6. EIS measurements of CF, PAni, and CF/PAni composites. 
frequency region the impedance response is associated with the electrode/electrolyte interface. The semicircle intersections with the real axis (Z') at high and at mid frequencies allow finding out the electrolyte and charge transfer resistances $\left(\mathrm{R}_{\mathrm{e}}\right.$ and $\left.\mathrm{R}_{\mathrm{ct}}\right)$, respectively.

In the low frequency regime, two different regions may occur. In the first region, the impedance response, ideally at $45^{\circ}$ straight line (Warburg impedance), represents the mass transfer parameters of the electrochemical doping process. In this region, the impedance is controlled by the counter-ions diffusion inside the composite electrode ${ }^{[36]}$. In the second region, the mass transport is limited, and the charge accumulation is favored indicating a pure capacitor behavior. In this case, the diffusion layer involves the entire electrode thickness. Particularly, the response (ideally at $90^{\circ}$ straight line) shows that $\mathrm{CF} / \mathrm{PAni}$ composites resemble a pure capacitor.

In order to analyse EIS results, the data were fitted using the equivalent circuit shown in Figure 7, where $R_{E}$ and $R_{C T}$ are the electrolyte and the charge-transfer resistances. The $\mathrm{CPE}_{1}$, the $\mathrm{CPE}_{2}$, and the $\mathrm{CPE}_{3}$ are the constant phase elements $^{[36]}$. The CPE was introduced as a replacement for the capacity in EIS measurements and are commonly used.

The fitting results based on the proposed equivalent circuit of $\mathrm{R}_{\mathrm{ct}}$ and $\mathrm{C}_{\mathrm{dl}}$ values are shown in Figure 8. We can clearly observe that the PAni insertion on the CF drastically decreased the Rct value getting too close to the Rct value of PAni powder. The Rct value for CF/PAni-30 was lower than those for CF/PAni-60 and CF/PAni-90 composites. This result also supports the hypothesis that a more cohesive interface

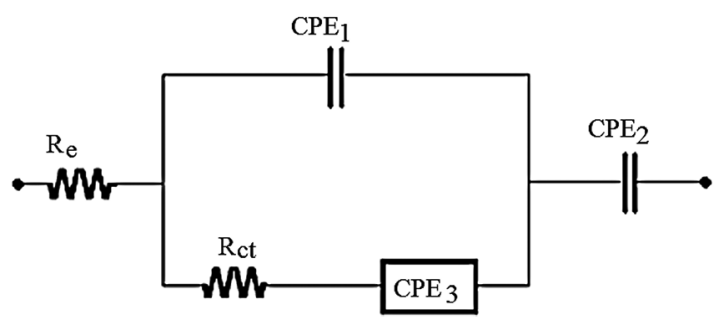

Figure 7. Equivalent circuit used to fit the EIS data for CF, PAni powder, and $\mathrm{CF} / \mathrm{PAni}$ composites.

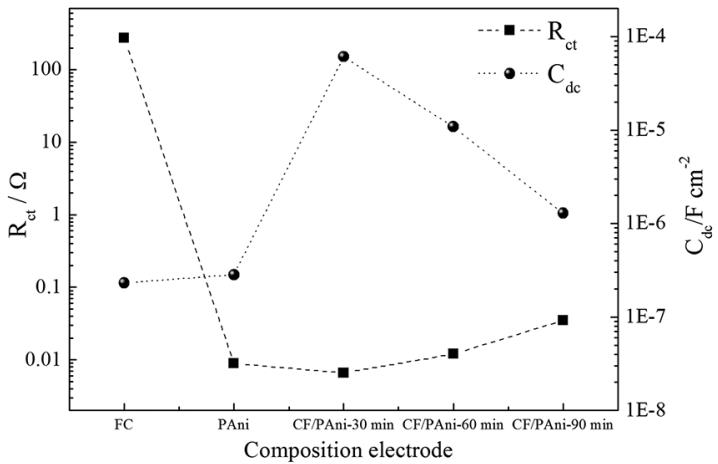

Figure 8. Variation of the specific capacitance according chargetransfer resistance. is formed between the CF and PAni for deposition time of $30 \mathrm{~min}$. Also, we can see that the double layer capacitance values for all composites were much higher than those obtained by their pure components, showing the synergism of this synthesis ${ }^{[37]}$.

A complementary analysis of the superior response of CF/PAni-30 electrode can also be observed in Figure 9 by the evaluated diffusion coefficient for PAni and for CF/PAni composite electrodes, from EIS measurements. The diffusion coefficient drastically increased when PAni is in the composite form also varying as a function of the polymer thickness with its maximum for the CF/PAni-30 electrode.

The specific capacitance of CF, PAni, and CF/PAni composites were obtained using galvanostatic chargingdischarging cycling of the electrodes for three different current densities. These results are shown in Figure 10 for current density of $\pm 1.0 \mathrm{~mA}$.

The CF/PAni composites showed good symmetry between the charge/discharge processes. For the electrodes of pure components, i.e. CF and PAni, we can observe that the time of the charge/discharge process is much shorter than those observed for the composite electrodes.

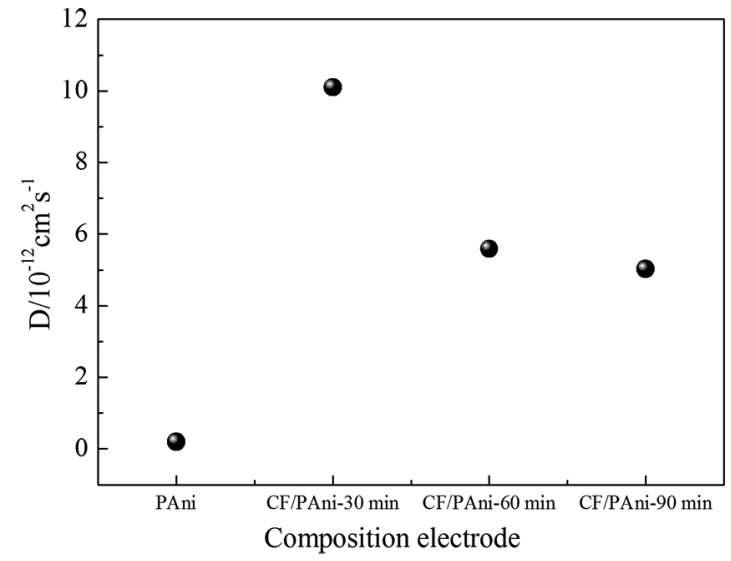

Figure 9. Diffusion coefficient for PAni and for CF/PAni composite electrodes.

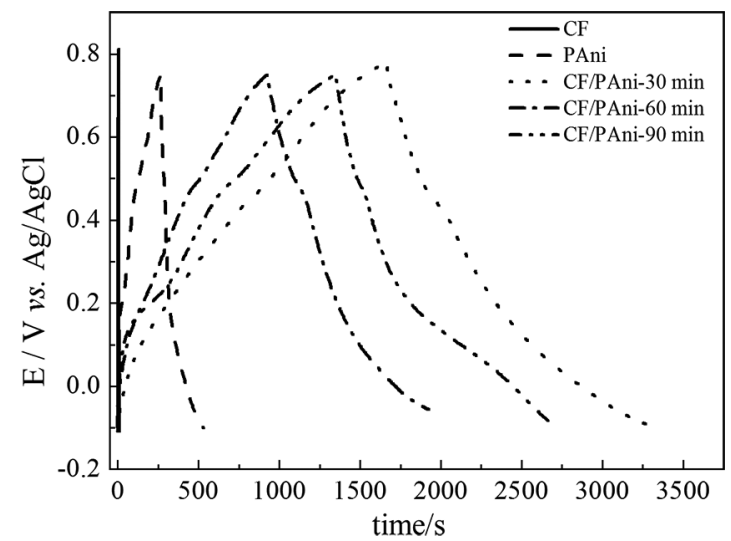

Figure 10. Charge and discharge curves of CF, PAni powder, CF/PAni - 30, CF/PAni - 60, and CF/PAni - 90. 


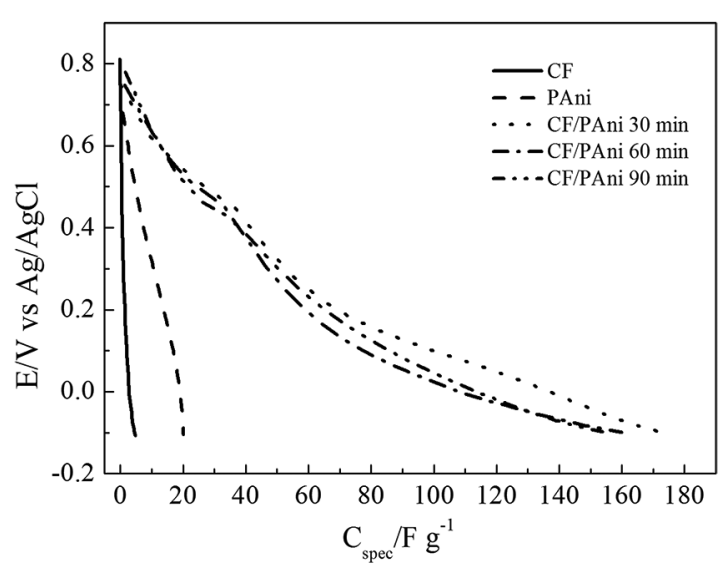

Figure 11. Specific Capacitance of of CF, PAni powder, CF/PAni - 30, CF/PAni - 60, and CF/PAni - 90 obtained from charge and discharge curves.

The specific capacitance values (Figure 11) can be calculated according to the following relationship in Equation 2:

$$
C_{s p}=i t / \Delta V m
$$

where $\boldsymbol{C s p}$ is the specific capacitance $\left[\mathrm{Fg}^{-1}\right], I$ is the charge/ discharge current, $t$ is the charge/discharge time, $\Delta V$ is the voltage difference between the upper and the lower potential limits, and $m$ is the mass of active material. The CF and the PAni electrodes showed lower specific capacitance values than those for the composite electrodes $\left(\mathrm{C}_{\mathrm{spCF}}=4.77\right.$ and $\mathrm{C}_{\text {spPAni }}=20.14 \mathrm{Fg}^{-1}$ ). In addition, as observed in the cyclic voltammetry, the highest specific capacitance was obtained for CF/PAni- 30 composite, $\left(\sim \mathrm{C}_{\mathrm{sp}}=180 \mathrm{Fg}^{-1}\right)$, making it a very strong candidate as supercapacitor electrode.

\section{Conclusion}

The CF/PAni composites from chemical synthesis process, at different deposition times, were obtained and characterized with success. From SEM analyses, CF/PAni-60 and CF/PAni-90 composites showed a micrometric thickness with polymeric clusters among the fibers. However, for CF/PAni-30 composite a nanometric thickness with a homogeneous morphology was obtained. The Raman spectra showed that the CF/PAni-30 composite seems to be more conductive than the other composites due to its more similar features to that for PAni itself. This fact was evidenced by the radical cation band, quite pronounced in this material. From cyclic voltammetry, it was possible to verify the highest electroactivity of the CF/PAni-30, due to its best electrochemical reversibility in the whole range of scan rates analyzed. This fact was confirmed by the EIS results, where CF/PAni-30 composite depicted the lowest charge transfer resistance value associated to its highest values for the double layer capacitance and for the diffusion coefficient. Furthermore, the charge/discharge testing showed a specific capacitance around $180 \mathrm{Fg}^{-1}$ for the CF/PAni-30 composite. These results showed that an effective coverage of PAni film on CF matrix occurred in the case of the CF/PAni-30 composite, promoting a decrease in the charge transfer resistance, making its charge/discharge process faster and more effective.

\section{Acknowledgements}

This work was supported by the CNPq proc number 150663/2010-2 and FAPESP proc number 2009/17584-0.

\section{References}

1. Hsu, C. T., Hu, C. C., Wu, T. H., Chen, J. C., \& Rajkumar, M. (2014). How the electrochemical reversibility of a batterytype material affects the charge balance and performances of asymmetric supercapacitors. Electrochimica Acta, 146, 759-768. http://dx.doi.org/10.1016/j.electacta.2014.09.041.

2. Burke, A. (2007). R\&D considerations for the performance and application of electrochemical capacitors. Electrochimica Acta, 53(3), 1083-1091. http://dx.doi.org/10.1016/j.electacta.2007.01.011.

3. Mastragostino, M., Arbizzani, C., \& Soavi, F. (2001). Polymerbased supercapacitors. Journal of Power Sources, 97-98, 812-815. http://dx.doi.org/10.1016/S0378-7753(01)00613-9.

4. Zhang, J., Kong, L. B., Wang, B., Luo, Y. C., \& Kang, L. (2009). In-situ electrochemical polymerization of multi-walled carbon nanotube/polyaniline composite films for electrochemical supercapacitors. Synthetic Metals, 159(3-4), 260-266. http:// dx.doi.org/10.1016/j.synthmet.2008.09.018.

5. Lota, K., Khomenko, V., \& Frackowiak, E. (2004). Capacitance properties of poly(3,4-ethylenedioxythiophene)/carbon nanotubes composites. Journal of Physics and Chemistry of Solids, 65(23), 295-301. http://dx.doi.org/10.1016/j.jpcs.2003.10.051.

6. Gupta, V., \& Miura, N. (2006). High performance electrochemical supercapacitor from electrochemically synthesized nanostructured polyaniline. Materials Letters, 60(12), 1466-1469. http://dx.doi. org/10.1016/j.matlet.2005.11.047.

7. Morvant, M. C., \& Reynolds, J. R. (1998). In situ conductivity studies of poly(3,4-ethylenedioxythiophene). Synthetic Metals, 92(1), 57-61. http://dx.doi.org/10.1016/S0379-6779(98)800234.

8. Hung, S. L., Wen, T. C., \& Gopalan, A. (2002). Application of statistical design strategies to optimize the conductivity of electrosynthesized polypyrrole. Materials Letters, 55(3), 165-170. http://dx.doi.org/10.1016/S0167-577X(01)00640-1.

9. Boara, G., \& Sparpaglione, M. (1995). Synthesis of polyanilines with high electrical conductivity. Synthetic Metals, 72(2), 135-140. http://dx.doi.org/10.1016/0379-6779(94)02337-X.

10. Li, H., Wang, J., Chu, Q., Wang, Z., Zhang, F., \& Wang, S. (2009). Theoretical and experimental specific capacitance of polyaniline in sulfuric acid. Journal of Power Sources, 190(2), 578-586. http://dx.doi.org/10.1016/j.jpowsour.2009.01.052.

11. Noh, K. A., Kim, D. W., Jin, C. S., Shin, K. H., Kim, J. H., \& Ko, J. M. (2003). Synthesis and pseudo-capacitance of chemically-prepared polypyrrole powder. Journal of Power Sources, 124(2), 593-595. http://dx.doi.org/10.1016/S03787753(03)00813-9.

12. Rudge, A., Davey, J., Raistrick, I., Gottesfeld, S., \& Ferraris, J. P. (1994). Conducting polymers as active materials in electrochemical capacitors. Journal of Power Sources, 47(1-2), 89-107. http:// dx.doi.org/10.1016/0378-7753(94)80053-7.

13. Olad, A., \& Gharekhani, H. (2015). Preparation and electrochemical investigation of the polyaniline/activated carbon nanocomposite for supercapacitor applications. Progress in Organic Coatings, 81, 19-26. http://dx.doi.org/10.1016/j.porgcoat.2014.12.009.

14. Jamadade, V. S., Dhawale, D. S., \& Lokhande, C. D. (2010). Studies on electrosynthesized leucoemeraldine, emeraldine 
and pernigraniline forms of polyaniline films and their supercapacitive behavior. Synthetic Metals, 160(9-10), 955960. http://dx.doi.org/10.1016/j.synthmet.2010.02.007.

15. Zhao, Z., Zheng, W., Yu, W., \& Long, B. (2009). Electrical conductivity of poly(vinylidene fluoride)/carbon nanotube composites with a spherical substructure. Carbon, 47(8), 2118-2120. http://dx.doi.org/10.1016/j.carbon.2009.03.043.

16. Park, J. H., Ko, J. M., Park, O. O., \& Kim, D. W. (2002). Capacitance properties of graphite/polypyrrole composite electrode prepared by chemical polymerization of pyrrole on graphite fiber. Journal of Power Sources, 105(1), 20-25. http:// dx.doi.org/10.1016/S0378-7753(01)00915-6.

17. Wu, M., Snook, G. A., Gupta, V., Shaffer, M., Fray, D. J., \& Chen, G. Z. (2005). Electrochemical fabrication and capacitance of composite films of carbon nanotubes and polyaniline. Journal of Materials Chemistry, 15(23), 2297-2303. http:// dx.doi.org/10.1039/b418835g.

18. Chen, G. Z., Shaffer, M. S. P., Coleby, D., Dixon, G., Zhou, W., Fray, D. J., \& Windle, A. H. (2000). Carbon nanotube and polypyrrole composites: coating and doping. Advanced Materials, 12(7), 522-526. http://dx.doi.org/10.1002/(SICI)15214095(200004)12:7<522::AID-ADMA522>3.0.CO;2-S.

19. Horng, Y. Y., Lu, Y. C., Hsu, Y. K., Chen, C. C., Chen, L. C., \& Chen, K. H. (2010). Flexible supercapacitor based on polyaniline nanowires/carbon cloth with both high gravimetric and areanormalized capacitance. Journal of Power Sources, 195(13), 4418-4422. http://dx.doi.org/10.1016/j.jpowsour.2010.01.046.

20. Xinping, H., Bo, G., Guibao, W., Jiatong, W., \& Chun, Z. (2013). A new nanocomposite: carbon cloth based polyaniline for an electrochemical supercapacitor. Electrochimica Acta, 111,210-215. http://dx.doi.org/10.1016/j.electacta.2013.07.226.

21. Basnayaka, P. A., Ram, M. K., Stefanakos, L., \& Kumar, A. (2013). Graphene/Polypyrrole nanocomposite as electrochemical supercapacitor electrode: electrochemical impedance studies. Graphene, 2(2), 81-87. http://dx.doi.org/10.4236/ graphene.2013.22012.

22. Boukamp, B. A. (1986). A nonlinear least squares fit procedure for analysis of immittance data of electrochemical systems. Solid State Ionics, 20(1), 31-44. http://dx.doi.org/10.1016/01672738(86)90031-7.

23. Boukamp, B. A. (1989). Equivalent Circuit: EQUIVCRT program-user's manual (Vol. 3). Enschede: University of Twente.

24. Wu, Q., Xu, Y., Yao, Z., Liu, A., \& Shi, G. (2010). Supercapacitors based on flexible graphene/polyaniline nanofiber composite films. ACS Nano, 4(4), 1963-1970. http://dx.doi.org/10.1021/ nn1000035. PMid:20355733.

25. Mažeikienė, R., Tomkutė, V., Kuodis, Z., Niaura, G., \& Malinauskas, A. (2007). Raman spectroelectrochemical study of polyaniline and sulfonated polyaniline in solutions of different pH. Vibrational Spectroscopy, 44(2), 201-208. http://dx.doi. org/10.1016/j.vibspec.2006.09.005.

26. Antunes, E. F., Lobo, A. O., Corat, E. J., Trava-Airoldi, V. J., Martin, A. A., \& Veríssimo, C. (2006). Comparative study of first- and second-order Raman spectra of MWCNT at visible and infrared laser excitation. Carbon, 44(11), 2202-2211. http://dx.doi.org/10.1016/j.carbon.2006.03.003.

27. Dresselhaus, M. S., Dresselhaus, G., Saito, R., \& Jorio, A. (2005). Raman spectroscopy of carbon nanotubes. Physics Reports, 409(2), 47-99. http://dx.doi.org/10.1016/j.physrep.2004.10.006.

28. Ko, T.H. (1996). Raman spectrum of modified PAN-based carbon fibers during graphitization. Journal of Applied Polymer Science, 59(4), 577-580. http://dx.doi.org/10.1002/(SICI)10974628(19960124)59:4<577::AID-APP2>3.0.CO;2-Q.

29. Morita, K., Murata, Y., Ishitani, A., Murayama, K., Ono, T., \& Nakajima, A. (1986). Characterization of commercially available PAN (polyacrylonitrile)-based carbon fibers. Pure and Applied Chemistry, 58(3), 455-68. http://dx.doi.org/10.1351/ pac198658030455

30. Furukawa, Y., Ueda, F., Hyodo, Y., Harada, I., Nakajima, T., \& Kawagoe, T. (1988). Vibrational spectra and structure of polyaniline. Macromolecules, 21(5), 1297-1305. http://dx.doi. org $/ 10.1021 / \mathrm{ma} 00183 \mathrm{a} 020$.

31. Nascimento, G. M., Constantino, V. R. L., \& Temperine, M. L.A. (2002). Spectroscopic characterization of a new type of conducting polymer-clay nanocomposite. Macromolecules, 35(20), 7535-7537. http://dx.doi.org/10.1021/ma0255711.

32. Bernard, M. C., \& Goff, A. H. L. (2006). Quantitative characterization of polyaniline films using Raman spectroscopy I: Polaron lattice and bipolaron. Electrochimica Acta, 52(2), 595-603. http://dx.doi.org/10.1016/j.electacta.2006.05.039.

33. Lapkowski, M., Berrada, K., Quillard, S., Louarn, G., Lefrant, S., \& Pron, A. (1995). Electrochemical oxidation of polyaniline in nonaqueous electrolytes: "in situ" raman spectroscopic studies. Macromolecules, 28(4), 1233-1238. http://dx.doi. org/10.1021/ma00108a061.

34. Yoon, S. B., Yoon, E. H., \& Kim, K. B. (2011). Electrochemical properties of leucoemeraldine, emeraldine, and pernigraniline forms of polyaniline/multi-wall carbon nanotube nanocomposites for supercapacitor applications. Journal of Power Sources, 196(24), 10791-10797. http://dx.doi.org/10.1016/j.jpowsour.2011.08.107.

35. Andrade, L. S., Rocha-Filho, R. C., Bocchi, N., \& Biaggio, S. R. (2004). Estudo de efeito dos sais precursores sobre as propriedades eletrocatalíticas de eletrodos de $\mathrm{Ti}-\mathrm{SnO}_{2} / \mathrm{Sb}$ preparados por decomposição térmica. Quimica Nova, 27(6), 866-872. http:// dx.doi.org/10.1590/S0100-40422004000600005.

36. MacDonald, D. D. (2006). Reflections on the history of electrochemical impedance spectroscopy. Electrochimica Acta, 51(8-9), 1376-1388. http://dx.doi.org/10.1016/j. electacta.2005.02.107.

37. Qaiser, A. A., Hyland, M. M., \& Patterson, D. A. (2011). Membrane potential and impedance studies of polyaniline composite membranes: effects of membrane morphology. Journal of Membrane Science, 385-386, 67-75. http://dx.doi. org/10.1016/j.memsci.2011.09.025.

Received: Nov. 13, 2014 Revised: Mar. 02, 2015 Accepted: Apr. 29, 2015 